\title{
Prevalence of Eating Disorders in Individuals with Type 2 Diabetes: A Cohort Comparison of Patients and Controls
}

\section{(ㅇ)(1) $(8)$}

\author{
Authors \\ Ricardo V. García-Mayor ${ }^{1}$, Francisco Javier García-Soidán², \\ Angel Salgado Barreira ${ }^{3}$, on behalf of the TRACONAL STUDY GROUP \\ Affiliations \\ 1 South Galicia Biomedical Foundation, University Hospital of Vigo, \\ Vigo, Spain \\ 2 Porriño Primary Care Centre, Vigo, Spain \\ 3 Research Unit, University Hospital of Vigo, Vigo, Spain \\ Key words \\ diabetes, alimentation, obesity \\ received 05.04 .2016 \\ revised 08.12 .2016 \\ accepted 08.02.2017 \\ Bibliography \\ DOI http://dx.doi.org/10.1055/s-0043-103347 \\ Published online: 13.4.2017 \\ Exp Clin Endocrinol Diabetes Rep 2017; 5: e7-e9 \\ (c) J. A. Barth Verlag in Georg Thieme Verlag KG Stuttgart - New York \\ ISSN 2196-7407 \\ Correspondence \\ Prof. Ricardo V. García-Mayor \\ South Galicia Biomedical Foundation \\ Alvaro Cunqueiro Hospital \\ Technic Block, 2 ${ }^{\text {nd }}$ floor \\ 341 Clara Campoamor Street \\ 36312 Vigo \\ Spain \\ Tel.: + 34/630/963866 \\ ricardo.garcia.mayor@sergas.es
}

\begin{abstract}
Aims To determine the prevalence of eating disorders (ED) in a cohort of patients with type 2 diabetes (T2DM), to identify the more predominant forms of ED, and to clarify if ED is associated with impaired metabolic control.

Methods A cohort of 517 patients with T2DM aged $\geq 40$ years and a control cohort of 304 patients without diabetes, age and gender matched, were enrolled from 3 primary care centres. All subjects completed the Questionnaire of Eating and Weight Patterns-Revised (QEWP-R), followed by a structured interview (EDE 17th version).

Results The overall prevalence of ED in patients with T2DM and control cohorts was $32.5 \%$ and $19.7 \%$, respectively $(p<0.001)$. The frequency of ED in the patients with T2DM cohort was significantly higher in male than in female: $61.9 \%$ vs. $38.1 \%$ of the ED, respectively $(p<0.001)$. The most prevalent form was unspecified feeding or eating disorder, mainly uncontrolled picking at food in $24.6 \%$ of subjects, which is significantly more prevalent in the patients with T2DM cohort than in controls, $24.6 \%$ vs. $14.5 \%$ ( $p<0.001)$. Mean $\mathrm{Hb}_{\mathrm{A} 1 \mathrm{c}}$ was $7.15 \% \pm 1.1 \%(55 \mathrm{mmol} /$ $\mathrm{mol}, 159 \mathrm{mg} / \mathrm{dL})$ and $6.84 \% \pm 1.1 \%(51 \mathrm{mmol} / \mathrm{mol}, 150 \mathrm{mg} / \mathrm{dL})$ in patients with T2DM with ED and without ED, respectively ( $p=0.047)$. Conclusions ED have a high prevalence in patients with T2DM, and the coexistence of type 2 diabetes and ED significantly affects metabolic control in these patients.
\end{abstract}

\section{Introduction}

People suffering from diabetes mellitus, need to make minor or major lifestyle adjustments. These adjustments can lead to either successful adherence to medical regimens and control of the disease or, on the contrary, to an ineffective or maladaptive coping [1]. Type 2 diabetes patients (T2DM) have to adhere to some responsibilities such as: modification of lifestyle (diet, exercise, and weight control), self-monitoring of blood glucose concentrations, foot care, and administration of medications. Difficulties in properly implementing these tasks can be associated with suboptimum glycemic control [2]. Comorbidity like psychological diseases such as depression, anxiety [3,4] and eating disorders [5] difficult the aforementioned lifestyle adjustments and are associated with bad metabolic control and vascular complications.
The association of eating disorders (ED) with diabetes is recognized in the scientific literature, but the majority of studies focus on ED in young females with type 1 diabetes mellitus $[6,7]$, whereas the more common type 2 diabetes mellitus disease has attracted substantially less interest. The aim of the present study was to determine the prevalence of ED in a type 2 diabetes patients cohort, to identify the more predominant forms of $E D$ in patients with T2DM, and to clarify if ED is associated with impaired metabolic control in these patients.

\section{Methods}

A cohort of 517 patients with type 2 diabetes aged $\geq 40$ years and a control cohort of 304 patients without diabetes, age and gender 
- Table 1 Prevalence of eating disorders in patients with type 2 diabetes compared with patients without diabetes.

\begin{tabular}{|c|c|c|}
\hline & $\begin{array}{c}\begin{array}{l}\text { T2DM Cohort } \\
\mathrm{N}=517\end{array}\end{array}$ & $\begin{array}{c}\text { Control Cohort } \\
N=304\end{array}$ \\
\hline Mean age (years) & $63.9 \pm 8.98$ & $60.1 \pm 9.43$ \\
\hline Female gender (\%) & 42.2 & 55.6 \\
\hline Mean BMI & $31.1 \pm 5.24$ & $28.3 \pm 4.25$ \\
\hline ED prevalence (\%) & 32.5 & $19.7^{*}$ \\
\hline Female & 38.1 & 68.3 \\
\hline Male & 61.9 & 31.7 \\
\hline BN & 0 & 0.3 \\
\hline BED & 0.6 & 0.3 \\
\hline OSFED & 5.8 & 3.6 \\
\hline UFED & 24.6 & $14.5^{*}$ \\
\hline \multicolumn{3}{|l|}{${ }^{*}=p<0.01$} \\
\hline \multicolumn{3}{|c|}{$\begin{array}{l}\text { BED: binge eating disorder; BMI: body-mass index; BN: bulimia } \\
\text { nervosa; ED: eating disorder; OSFED: other specified feeding or } \\
\text { eating disorder; T2DM: type } 2 \text { diabetes mellitus; UFED: unspecified } \\
\text { feeding or eating disorder }\end{array}$} \\
\hline
\end{tabular}

matched, were enrolled from 3 primary care centres. Exclusion criteria: personal history of psychiatric diseases and/or use of psychotropic drugs, by their Primary Care Physician after consulting their medical history. All patients were living in the region of Pontevedra, a province in the Northwest of Spain, which recorded 958428 inhabitants in the 2012 official census. All subjects completed the Questionnaire of Eating and Weight Patterns-Revised (QEWP-R), followed by a structured interview (EDE 17th version to diagnosis of ED with DSM-5 criteria) [8]. These studies were carried out by 3 experienced psychologists who were members of the study group. Eating disorders involve serious disturbances in eating behavior, such as extreme and unhealthy reduction of food intake or severe overeating, as well as feelings of distress or extreme concern about body shape or weight. Eating Disorders in DSM-5 consider the follow clinical entities: Anorexia Nervosa (AN), Bulimia Nervosa (BN), Binge Eating Disorder, Pica, Rumination Disorder, Avoidant/Restrictive Food Intake Disorder (ARFID), Other Specified Feeding or Eating Disorder (OSFED) and Unspecified Feeding or Eating Disorder (UFED) [9].

Study variables were: presence/absence of T2DM, ED rates, body mass index (BMI), and serum glycosylate haemoglobin $\left(\mathrm{Hb}_{\mathrm{A} 1 \mathrm{c}}\right)$ concentration measured by high performance liquid chromatography (HPLC), as required by DCCT standards.

\section{Results}

The overall prevalence of ED in the patients with T2DM and control cohorts was $32.5 \%$ and $19.7 \%$, respectively $(p<0.001)$. The frequency of ED in the patients with T2DM cohort was significantly higher in male than in female patients: $61.9 \%$ vs. $38.1 \%$ of patients with ED, respectively $(p<0.001)$. With regard to the specific kind of ED based on DSM-5, the most prevalent form was unspecified feeding or eating disorder (UFED) in $24.6 \%$ of patients with T2DM, followed by other specified feeding or eating disorder (OSFED) in
$5.8 \%$. When we compared the prevalence of these forms of ED between both cohorts, we found that only UFED is significantly more prevalent in the patients with T2DM cohort, $24.6 \%$ vs. $14.5 \%$ $(p<0.001)$ ( Table 1). Mean $\mathrm{Hb}_{\mathrm{A} 1 \mathrm{c}}$ was $7.15 \% \pm 1.1 \%(55 \mathrm{mmol} /$ $\mathrm{mol}, 159 \mathrm{mg} / \mathrm{dL})$ and $6.84 \% \pm 1.1 \%(51 \mathrm{mmol} / \mathrm{mol}, 150 \mathrm{mg} / \mathrm{dL})$ in patients with T2DM with ED and without ED, respectively $(p=0.047)$.

\section{Discussion}

Studies report a wide range prevalence of ED in patients with T2DM: binge eating disorder (BED) from $2.5 \%$ to $40 \%$ [10-13], Subclinical-BED (Sub-BED) from $7 \%$ to $20 \%[5,11,14,15]$, and Night Eating Syndrome (NES) $3.8 \%$ [16]. However, these studies didn't have a control group with patients without diabetes.

In the present investigation a significantly higher prevalence of ED was observed among patients with T2DM, compared with patients without T2DM from the same population. In contrast with findings in patients with type 1 diabetes and adults without diabetes, ED were more prevalent in males than in females with T2DM. The most prevalent forms of ED based on DSM-5 criteria were UFED (mainly uncontrolled picking at food), OSFED (including incomplete forms of BED and night eaters), and BED, both in patients and controls. Contrary to some previous studies $[11,17]$, we have observed significant high levels of $\mathrm{Hb}_{\mathrm{A} 1 \mathrm{c}}$ in the group of patients with T2DM with ED compared with those without ED, indicating that the coexistence of type 2 diabetes and ED significantly affects metabolic control in these patients. The results of this study indicate the need to rule out any eating disorder in patients with type 2 diabetes poorly compensated.

\section{Acknowledgments}

We would like to acknowledge the assistance of Alvarez-Farinas $L$, Del Pozo S, Fluiters E, Larranaga A.

\section{Conflict of interest}

None.

\section{References}

[1] Stanton AL, Collins CA, Sworowski LA. Adjustment to chronic illniess: Theory and research. In: Handbook of health psychology. Baum A, Revenon TA, Singer JS (eds.). pp 387-403 Mahway Nk: Erlbaum; 2001

[2] UK Prospective Diabetes Study Group. Intensive blood glucose control with sulphonylureas or insulin compared with conventional treatment and risk complications in patients with type 2 diabetes. Lancet 1998; 352: 837-853

[3] Gavard J, Lustman P, Clouse R. Prevalence of depression in adults with diabetes: an epidemiological evaluation. Diabetes Care 1993; 16: 1167-1178

[4] de Groot M, Jacobson A, Samson J et al. Glycemic control an major depression in patients with type 1 and type 2 diabetes mellitus. J Psychosom 1999; 46: 425-435 1999 
[5] Kenardy J, Mensch M, Bowen $\mathrm{K}$ et al. A comparison of eating behaviours in newly diagnosed NIDDM patients and case-matched control subjects. Diabetes Care 1994; 17: 1197-1199

[6] Larrañaga A, Garcia-Mayor RV. Disordered eating behaviors in type 1 diabetics. WJD 2011; 2: 189-195

[7] Young V, Eiser C, Johnson B et al. Eating problems in adolescents with type 1 diabetes: A systematic review with meta-analysis. Diabet Med 2013; 30: 189-198

[8] Fairburn CG, Cooper Z, O'Connor ME. Eating disorder examination, edition 17.OD. The Center for Research in Dissemination at Oxford April 2014. Available at: http://www.credo-oxford.com/pdfs/ EDE_17.0D.pdf

[9] American Psychiatric Association. Diagnostic and statistical manual of mental disorders. $5^{\text {th }}$ Ed. Arlington, VA: American Psychiatric Publishing; 2013

[10] Herpertz S, Albus C, Lichtblau K et al. Relationship of weight and eating disorders in type 2 diabetic patients: A multicentre study. Int ] Eat Disrod 2000; 28: 68-77

[11] Crow S, Kendall D, Praus B et al. Binge eating and other psychopathology in patients with type II diabetes mellitus. Int J Eat Disord 2001; 30: $222-226$
[12] Mannucci E, Tesi F, Ricca $V$ et al. Eating behaviour in obese patients with and without type 2 diabetes mellitus. Int J Obes Relat Metab Disord 2002; 26: 848-853

[13] Menneghini LF, Spadola J, Florez H. Prevalence and associations of Binge Eating Disorder in a Multiethnic population with type 2 diabetes. Diabetes Care 2006; 29: 2760

[14] TODAY study. Binge eating, mood and quality of life in youth with type 2 diabetes. Diabetes Care 2011; 34: 858-860

[15] Kenardy J, Mensch M, Bowen K et al. Disordered eating in type 2 diabetes. Eating Behav 2001; 2: 183-192

[16] Allison K, Crow SJ, Reeves RR et al. Binge eating disorder and Nigth Eating Syndrome in adults with type 2 diabetes. Obesity 2007; 15: 1287-1293

[17] Wing RR, Marcus MD, Epstein LH et al. Binge eating in obese patients with type 2 diabetes. Int J Eat Disord 1989; 8: 671-679 